\title{
Differential Effects of Cysteine and Histidine-Capped ZnS:Mn Nanocrystals on Escherichia coli and Human Cells
}

\author{
Hoon Young Kong, ${ }^{\dagger}$ Song-Yi Kim, ${ }^{\ddagger,}$ Jonghoe Byun, ${ }^{\dagger, *}$ and Cheong-Soo Hwang ${ }^{\ddagger, \beta, *}$ \\ Department of Molecular Biology ${ }^{\dagger}$ and Department of Chemistry, ${ }^{\ddagger}$ Institute of Nanosensor and Biotechnology, \\ Center for Photofunctional Energy Materials (GRRC), ${ }^{\S}$ Dankook University, Gyeonggi-do 448-701, Korea \\ "E-mail: cshwang@dankook.ac.kr (C.-S.H.); jonghoe@dankook.ac.kr (J.B) \\ Received August 16, 2010, Accepted October 21, 2010
}

\begin{abstract}
Cysteine and histidine-capped water-dispersible ZnS:Mn nanocrystals (ZnS:Mn-Cys and ZnS:Mn-His) were synthesized and their effects on $E$. coli and human cells were investigated. Particle sizes of these nanocrystals were found from HR-TEM images to be $3.5 \mathrm{~nm}$ and $4.0 \mathrm{~nm}$, respectively. Their solution photoluminescence spectra showed identical broad emission peaks at $580 \mathrm{~nm}$. ZnS:Mn-His significantly suppressed the growth of E. coli at $100 \mu \mathrm{g} / \mathrm{mL}$ and $1 \mathrm{mg} / \mathrm{mL}$ concentrations, something not observed with ZnS:Mn-Cys. Consistent with this, greater inhibition of cell proliferation and viability were observed in HEK293 and IMR90 cells in ZnS:Mn-His at $100 \mu \mathrm{g} / \mathrm{mL}$ and $1 \mathrm{mg} / \mathrm{mL}$ concentrations.
\end{abstract}

Key Words: ZnS:Mn nanocrystal, Amino acid capping, Cytotoxicity, E. coli, Human cells

\section{Introduction}

Semiconducting nanocrystals have received significant interest in the last decade. ${ }^{1,2}$ These nano-sized and quantum confined materials have found many applications in non-linear optics and electronic devices and, more recently, in advanced biotechnology due to their unique physical, chemical and optical properties. ${ }^{3,4}$ A representative example is an orange-light emitting manganese-ion doped $\mathrm{ZnS}$ nanocrystallite (ZnS:Mn) that exhibits both high photoluminescent efficiency and thermal stability at ambient temperature, critical properties required for commercial electro-luminescence devices. ${ }^{5}$ Considerable progress in the preparation methods of such materials has also been made. Routes include the use of gas, solid, and aqueous solution reactions via organometallic precursors. However, these methods often require high temperatures, pressures and even the use of bio-hazardous substances. ${ }^{6}$

Recently, a few semiconductor nanocrystals, such as CdSe and CdS, have been developed for fluorescent labeling, a potentially useful biomedical application. ${ }^{7,8}$ Although they exhibit much greater photostability than commercial organic dyes, they have two significant problems when directly applied in vivo. First, semiconductor nanocrystals containing metal ions such as cadmium or selenide are, unless contained, toxic to human health. In spite of its importance, there are few studies regarding their toxicities or safety in living organisms. ${ }^{9}$ Second, since most highly luminescent semiconductor nanocrystals are grown in hydrophobic media, they are incompatible with mainly hydrophilic biological systems. To overcome this, their surface properties, or indeed the semiconductor nanocrystals themselves, should be modified. In this regard, there are several reports on solubilized hydrophobic nanocrystals in water. ${ }^{10,11}$ The literature's most commonly cited synthetic scheme for water dispersible nanocrystals uses polar surface capping ligands, such

*These corresponding authors contributed equally to this work. as mercaptoacetate (MAA) and sulfodiisooctyl succinate (AOT) molecules, to form a micelle structure with negative charges distributed on its surface. In addition, it has been shown that the photoluminescence efficiency for AOT capped $\mathrm{ZnS}: \mathrm{Mn}$ nanocrystals increases several fold after surface modification. ${ }^{12}$

More recently, amino acid ligands such as histidine ${ }^{13}$ and cysteine ${ }^{14}$ have been developed as surface capping agents for semiconductor nanocrystals, such as undoped $\mathrm{ZnS}$. These ligands were found to cap effectively in the synthesis of nanocrystals of narrow size distribution, something difficult to achieve in aqueous solution due to the different dissociation constants for $\mathrm{ZnS}$ in water. A detailed procedure for the synthesis of cysteineand histidine-coordinated $\mathrm{ZnS}$ nanocrystals has been previously reported. ${ }^{15}$ In this study, physical and optical characterization of ZnS:Mn-Cys and ZnS:Mn-His were carried out. Also performed was a comparative toxicological study of the two amino acidcapped $\mathrm{ZnS}: \mathrm{Mn}$ nanocrystals in $E$. coli bacteria and mammalian cells. Interestingly, different effects of $\mathrm{ZnS}: \mathrm{Mn}-\mathrm{Cys}$ and $\mathrm{ZnS}$ : Mn-His on biological system were observed, suggesting a novel perspective in the design of biocompatible $\mathrm{ZnS}$ :Mn nanocrystals.

\section{Experimental Section}

Instrumentation. UV-vis absorption spectra were recorded using a Perkin Elmer Lamda 25 spectrophotometer equipped with a deuterium/tungsten lamp. The FT-IR spectra were obtained using a Perkin Elmer spectrophotometer equipped an attenuated total reflection (ATR) unit. Solution photoluminescence spectra were taken by a Perkin Elmer LS- 45 spectrophotometer equipped with a $500 \mathrm{~W}$ Xenon lamp, $0.275 \mathrm{~m}$ triple grating monochrometer, and PHV 400 photomultiplier tube. HR-TEM images were taken with a JEOL JEM 1210 electron microscope with a MAG mode of 1,000 to 800,000 . The accelerating voltage was $40-120 \mathrm{kV}$. Samples for TEM were prepared via dispersion in methanol and placement on a carbon-coated 
copper grid (300 Mesh) followed by drying under vacuum. In addition, elemental compositions of the nanocrystals were determined by an Energy Dispersive X-ray Spectroscopy (EDXS) collecting unit equipped in the HR-TEM, with a $\mathrm{Si}$ (Li) detector in IXRF 500 system.

Chemicals and Reagents. All solvents, except deionized water, were purchased from Aldrich (reagent grade) and distilled prior to use. All reactants, including L-cysteine, L-histidine, $\mathrm{ZnSO}_{4}, \mathrm{MnSO}_{4}$, and $\mathrm{Na}_{2} \mathrm{~S}$, were purchased from Aldrich and used as received. The E. coli $\mathrm{K}-12$ (wild type strain) was purchased from the Korean Culture Center of Microorganisms (KCCM 40939) and the IMR90 and HEK293 were purchased from The American Type Culture Collection (CCL-186 \& CRL1573, respectively).

Synthesis of Amino Acid-Capped ZnS:Mn Nanocrystals. A previously reported aqueous synthesis of histidine and cysteine capped $\mathrm{ZnS}: \mathrm{Mn}$ nanocrystals via the formation of zinc (II)amino acid coordinated complexes as reactive intermediates was followed with slight modification. ${ }^{16} \mathrm{~A} 50 \mathrm{~mL}$ aqueous solution of $\mathrm{ZnSO}_{4} \cdot 5 \mathrm{H}_{2} \mathrm{O}(1.44 \mathrm{~g}, 5 \mathrm{mmol})$ was slowly added to a $50 \mathrm{~mL}$ aqueous solution containing $10 \mathrm{mmol}$ of amino acids and $\mathrm{NaOH}(0.40 \mathrm{~g}, 10 \mathrm{mmol})$ at $5{ }^{\circ} \mathrm{C}$ (ice-water bath). The solution was warmed to ambient temperature after 1 hour's stirring. Separate from this, $\mathrm{MnSO}_{4} \cdot \mathrm{H}_{2} \mathrm{O}(0.02 \mathrm{~g}, 0.1 \mathrm{mmol})$ and $\mathrm{Na}_{2} \mathrm{~S}$ $(0.40 \mathrm{~g}, 5 \mathrm{mmol})$ were dissolved in $20 \mathrm{~mL} 0.01 \mathrm{M} \mathrm{HCl}$. This mixture was subsequently transferred to the flask containing the $\mathrm{Zn}$-amino acid complexes under vigorous stirring. The resulting solution was refluxed for 10 hours. Slow cooling to ambient temperature and the addition of ethanol resulted in a yellow-white precipitate at the bottom of the flask. Finally, the obtained solids were separated by centrifuging and decanting the supernatant. The solids were then dried for 24 hours in a vacuum oven. The experimental data are summarized in Table 1.

Batch Culture of Escherichia coli. E. coli K-12 strain was grown in $10 \mathrm{~mL}$ of nutrient broth (beef extract $3 \mathrm{~g} / \mathrm{L}$, peptone $5 \mathrm{~g} / \mathrm{L}$ ) with shaking at $37^{\circ} \mathrm{C}$ for $16 \mathrm{hrs}$, both in the absence and presence of the nanocrystals. The nanocrystals were dissolved in the nutrient broth to give a concentration of $20 \mathrm{mg} / \mathrm{mL}$ and this stock solution was used to achieve different concentrations in the bacterial culture ( 0 to $1 \mathrm{mg} / \mathrm{mL}$ ). To plot growth, the turbidity of the culture was checked every 30 min by measuring optical density at $600 \mathrm{~nm}$ using SpectraMax M2e microplate reader (Molecular Devices). The study was performed in triplicate.

IMR90 and HEK293 Cell Culture. The lung fibroblasts (IMR 90) and human embryonic kidney cells (HEK293) were cultivated in minimal essential medium (MEM) containing 10\% (v/v) fetal bovine serum (Gibco BRL) under humidified atmosphere of $5 \% \mathrm{CO}_{2}$ at $37{ }^{\circ} \mathrm{C}$. For the viability assay, IMR90 or HEK293 cells were seeded in a 96-well plate at a density of $3 \times$ $10^{3}$ cells/well. After $24 \mathrm{hrs}$, when the cells were firmly attached, the nanocrystals (stock solutions: fresh MEM containing 20 $\mathrm{mg} / \mathrm{mL}$ nanocrystals) were added to the medium to obtain concentrations in a range of 0 to $1 \mathrm{mg} / \mathrm{mL}$ and incubated for additional $24 \mathrm{hrs}$. The viability of the cells was then measured by WST-1 assay (Takara, WST-1 PreMix solution) according to manufacturer's instruction. This being briefly: the culture medium was removed and the fresh medium containing $10 \%(\mathrm{v} / \mathrm{v})$
WST-1 solution was added to the cells, followed by $1 \mathrm{hr}$ incubation at $37^{\circ} \mathrm{C}$. The plates were read at $470 \mathrm{~nm}$ using a SpectraMax M2e microplate reader (Molecular Devices).

Statistical Analysis. The data were expressed as means \pm SEM. Results were analyzed with GraphPad Prism statistics software (GraphPad Software, Inc., San Diego, CA, USA). Student's $t$-test was used to evaluate statistical differences between the groups. A $P$ value of less than 0.05 was considered statistically significant.

\section{Result and Discussions}

This study evaluates the toxicity profiles of water-dispersible $\mathrm{ZnS}: \mathrm{Mn}$ nanocrystals whose surfaces had been modified with the conventional amino acids cysteine and histidine. Prior to biological evaluation, the physical and optical characteristics of the nanocrystals were examined. The particle sizes of the corresponding amino acid-capped $\mathrm{ZnS}: \mathrm{Mn}$ nanocrystals were measured from the HR-TEM images (Fig. 1(a) and 1(b)). The images show fairly homogeneous spherical particles of $3.5 \mathrm{~nm}$ (ZnS:Mn-Cys) and $4.0 \mathrm{~nm}$ (ZnS:Mn-His). In addition, Figs. 2(a) and (b) show the results of energy dispersive X-ray spectroscopy (EDXS) elemental analysis of the solid products. The presence of zinc, sulfur and manganese were confirmed besides the large amounts of carbon and oxygen atoms in the powder samples. In addition, EDXS analysis showed that the doping percentages of the manganese ions in the measured $\mathrm{ZnS}: \mathrm{Mn}$ nanoparticles were $0.6 \%$ (ZnS:Mn-Cys) and $0.7 \%$ (ZnS:Mn-His). The manganese (II) ion doping concentration in the $\mathrm{ZnS}$ :Mn crystals was designed to be approximately $1.0 \%$, a previously reported optimum of PL efficiency for other ligand-capped $\mathrm{ZnS}: \mathrm{Mn}$ nanocrystals. $^{17}$

Optical properties of the ZnS:Mn-Cys and ZnS:Mn-His nanocrystals were measured via room temperature solution photoluminescence (PL) spectroscopy, as shown in Fig. 3. The solution PL spectra, obtained from the amino acid-capped $\mathrm{ZnS}: \mathrm{Mn}$ in aqueous solution, showed broad emission peaks appeared at $580 \mathrm{~nm}$ for both $\mathrm{ZnS}: \mathrm{Mn}$ nanocrystals. The corresponding emission spectra were obtained when the excitation wave lengths were fixed at corresponding UV-vis absorption peaks (Table 1). The second-order diffraction peaks of the excitation and emission wavelengths appeared at $305 \mathrm{~nm}$ and $610 \mathrm{~nm}$, respectively. The observed large Stokes shifts (approximately $260 \mathrm{~nm}$ ) for the amino acid-capped $\mathrm{ZnS}: \mathrm{Mn}$ nanocrystals are typical of nano-
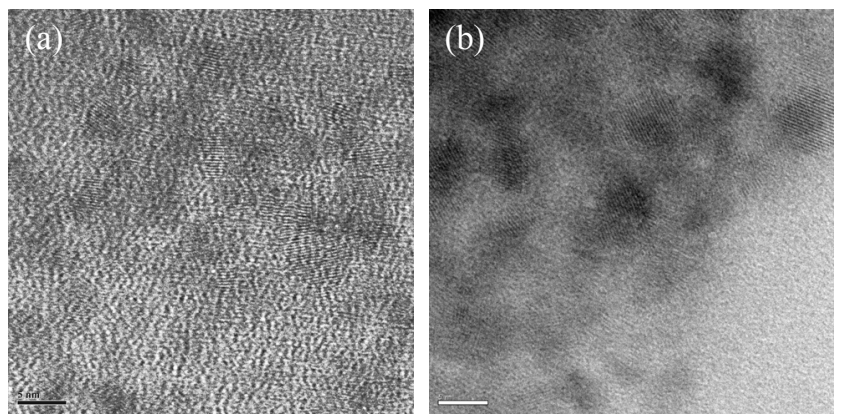

Figure 1. HR-TEM image of: (a) ZnS:Mn-Cys and (b) ZnS:Mn-His nanocrystals. 


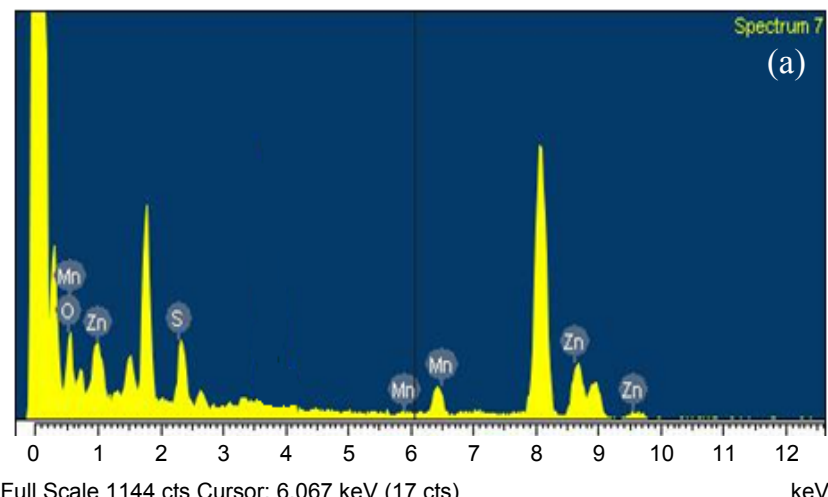

Full Scale 1144 cts Cursor: 6,067 keV (17 cts)

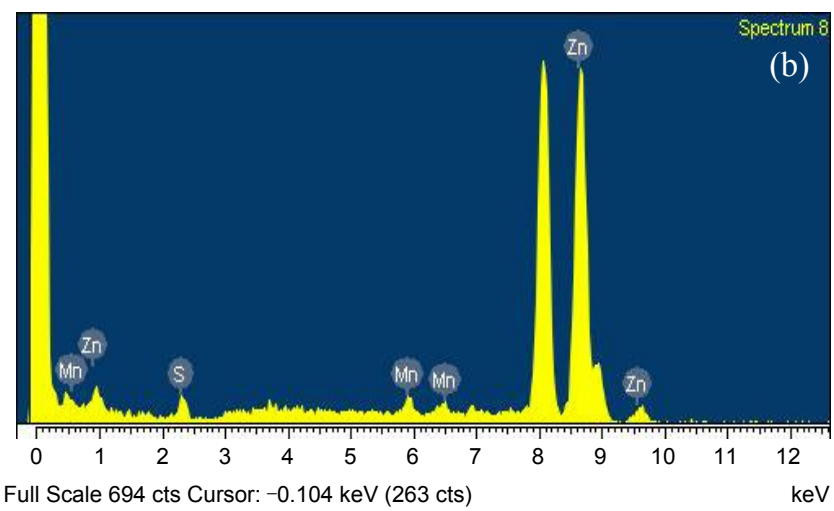

Figure 2. Energy dispersive x-ray spectroscopy (EDXS) diagrams of: (a) ZnS:Mn-Cys and (b) ZnS:Mn-His nanocrystals.

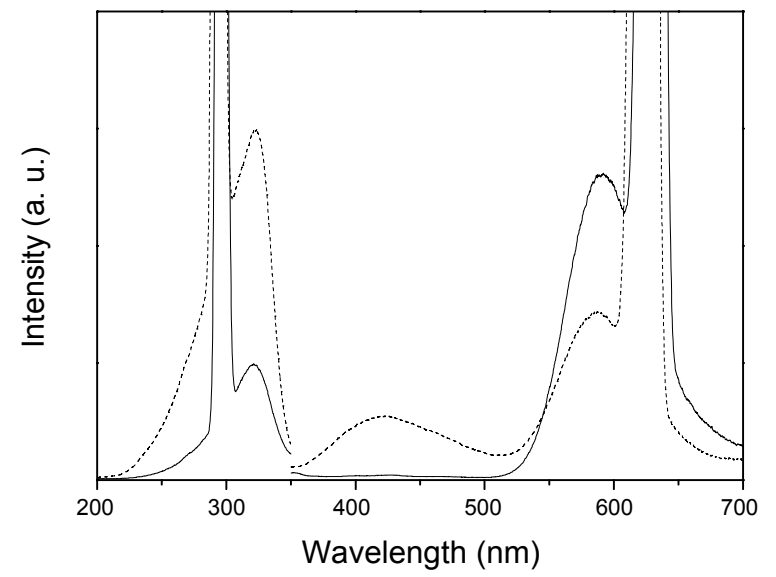

Figure 3. Room temperature aqueous solution photoluminescence spectra (excitation and emission) of ZnS:Mn-Cys (solid line) and ZnS: Mn-His (dots).

sized crystalline materials. The small broad peak at $420 \mathrm{~nm}$ for $\mathrm{ZnS}: \mathrm{Mn}-\mathrm{His}$ is known to be a defect arising from zinc ion vacancy in the $\mathrm{ZnS}$ crystal lattice, ${ }^{18}$ indicating that Histidine is a less effective surface capping agent than Cysteine. The PL peak intensity of $\mathrm{ZnS}$ :Mn-Cys was much higher than that of $\mathrm{ZnS}: \mathrm{Mn}-\mathrm{His}$, indicating that cysteine is more effective at surface capping for the $\mathrm{ZnS}: \mathrm{Mn}$ nanocrystals. This implies that fewer $\mathrm{Zn}^{2+}$ ions were dissociated from the nanocrystal into the aqueous solvent, promising safer application. To confirm the PL emission intensity difference between nanocrystals capped
Table 1. Data summary for the amino acid-capped ZnS:Mn nanocrystals

\begin{tabular}{ccc}
\hline & ZnS:Mn (Cysteine) & ZnS:Mn (Histidine) \\
\hline UV-vis $\left(\lambda_{\max }, \mathrm{nm}\right)$ & 322 & 321 \\
PL emission & 580 & 580 \\
wavelength $(\mathrm{nm})$ & & \\
PL efficiency $(\%)$ & 6.5 & 3.4 \\
Mn doping $(\%)$ & 0.6 & 0.7 \\
& $3232(\mathrm{~s}), 2918(\mathrm{~m})$, & $3248(\mathrm{~s}), 2916(\mathrm{~m})$, \\
& $2638(\mathrm{w}), 2160(\mathrm{w})$, & $1582(\mathrm{~s}), 1474(\mathrm{~m})$, \\
FT-IR $v\left(\mathrm{~cm}^{-1}\right)$ & $2050(\mathrm{w}), 1576(\mathrm{~s})$, & $1406(\mathrm{~s}), 1340(\mathrm{~m})$, \\
& $1396(\mathrm{~s}), 1352(\mathrm{~m})$, & $1238(\mathrm{w}), 1112(\mathrm{~m})$, \\
& $1296(\mathrm{~m}), 1222(\mathrm{w})$, & $1046(\mathrm{~m}), 978(\mathrm{~m})$, \\
& $1056(\mathrm{~s}), 920(\mathrm{~m})$ & $935(\mathrm{w}), 820(\mathrm{~m})$ \\
\hline
\end{tabular}

with the two amino acids, PL efficiencies for the corresponding nanocrystals were also investigated. The PL efficiencies of each capped nanocrystal samples were measured and calculated using the method reported by Williams et al. ${ }^{19}$ This method involves calculating the relative quantum yield through a comparison with a standard material, $0.1 \mathrm{M}$ aqueous solution of L-Tyrosine, whose excitation wavelength and absolute quantum yield were respectively reported to be $275 \mathrm{~nm}$ and $14 \%$ (at $\left.22{ }^{\circ} \mathrm{C}\right)$. The obtained relative PL efficiencies of $6.5 \%(\mathrm{ZnS}$ : Mn-Cys) and 3.4\% (ZnS:Mn-His) strongly suggest that Cysteine possesses much greater surface capping ability for $\mathrm{ZnS}: \mathrm{Mn}$ nanocrystals than Histidine.

The wide angle $\mathrm{X}$-ray diffraction patterns of powder samples of the amino acid-capped $\mathrm{ZnS}: \mathrm{Mn}$ nanocrystals were obtained. Although some of the peaks are too broad to be exactly assigned, especially for the $\mathrm{ZnS}: \mathrm{Mn}-\mathrm{Cys}$ nanocrystals, it is generally known that they are quite common features of most low-dimensional nano-sized materials. ${ }^{4}$ Even so, there were clearly indexable (008), (110) and (118) peaks in the spectra indicating that all the amino acids-capped $\mathrm{ZnS}: \mathrm{Mn}$ nanocrystals are in hexagonal wurtzite phases in the space group of $\mathrm{Pb}_{3} m c^{20}$

In addition, the corresponding amino acid molecules on the surfaces of the $\mathrm{ZnS}$ :Mn nanocrystals were characterized by FT-IR spectroscopy. All obtained peak data are listed in Table 1. The strong peaks that appeared near $2918 \mathrm{~cm}^{-1}$ and $1580 \mathrm{~cm}^{-1}$ were assigned as zinc coordinated $-\mathrm{NH}_{2}$ and $-\mathrm{COO}^{-}$groups of the amino acids. ${ }^{21}$ However, it is also possible that the peaks at around $2918 \mathrm{~cm}^{-1}$ also overlapped with that for the C-H stretching bands in the amino acid molecules. To remove any uncoordinated or unreacted amino acid molecules, the centrifuged white solids were rapidly washed several times with cold alcohol/water solutions. As a result, the peaks that resulted from the precursors, free amino acid molecules, could be removed from the presented FT-IR spectra. In addition, the spectra indicated that all the amino acid ligands were attached to the surface of the ZnS:Mn nanocrystals, which can provide water dispersibilty to the originally hydrophobic $\mathrm{ZnS}: \mathrm{Mn}$ nanocrystals.

Since cysteine and histidine-capped water-soluble $\mathrm{ZnS}: \mathrm{Mn}$ semiconductor nanocrystals were successfully synthesized, their toxic effects in a typical enteric bacterium, Escherichia coli (E. coli), were also tested. By comparing the growth curve of E. coli batch culture in the presence and absence of $\mathrm{ZnS}: \mathrm{Mn}-\mathrm{Cys}$ 
(A)

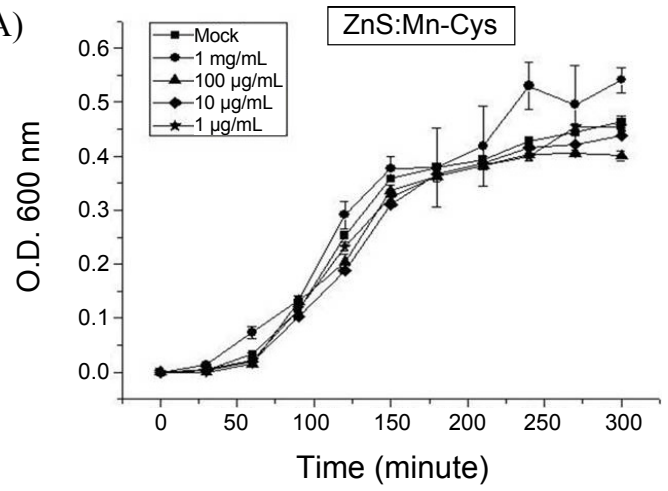

(B)

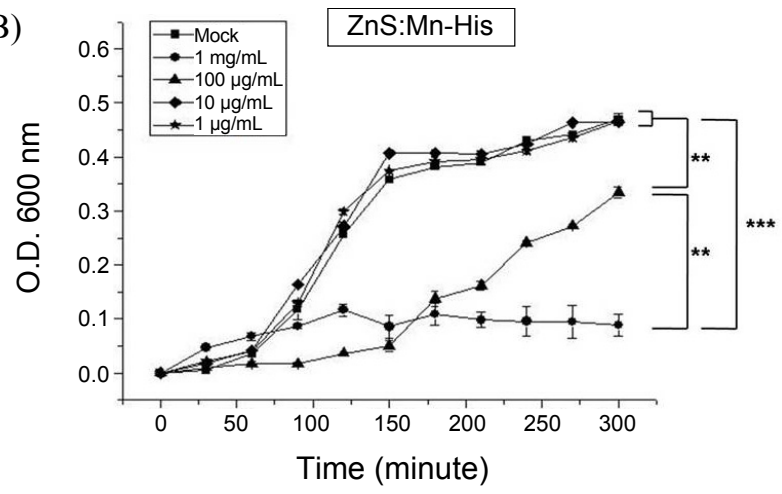

(C)

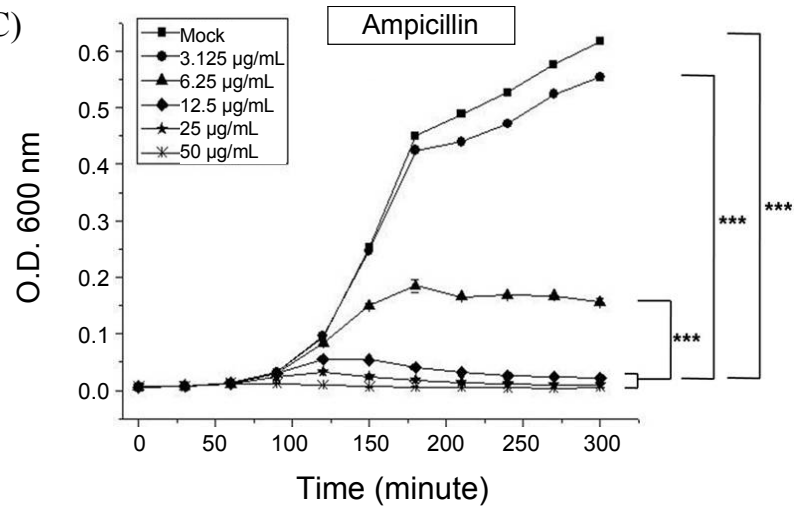

(D)

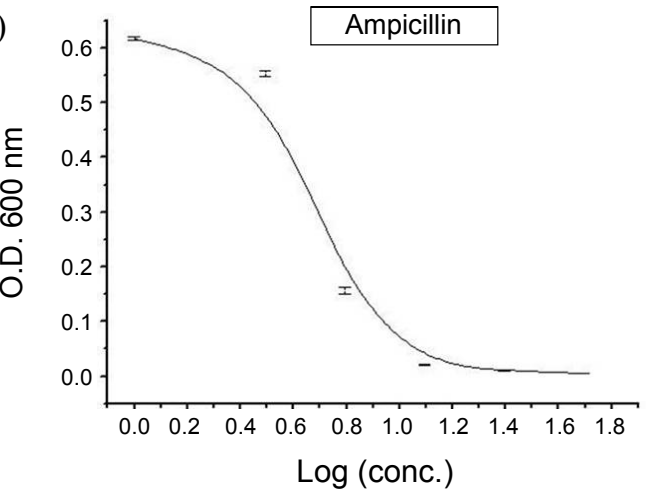

Figure 4. Effect of cysteine (A) and histidine (B) capped ZnS:Mn nanocrystals on growth of E. coli. Ampicillin (C) was also evaluated for growth inhibition and its $\mathrm{IC}_{50}$ was estimated (D).

or ZnS:Mn-His, any cytotoxic effects of the nanocrystals could be examined. Interestingly, as shown in Figure 4, suppression of E. coli growth was observed with $\mathrm{ZnS}: \mathrm{Mn}-\mathrm{His}$ at concentrations of $100 \mu \mathrm{g} / \mathrm{mL}$ and $1 \mathrm{mg} / \mathrm{mL}$. The difference in bacterial turbidity (O.D. $600 \mathrm{~nm}$ ) at 5 hrs between mock/low dose group and high dose group $(100 \mu \mathrm{g} / \mathrm{mL}$ and $1 \mathrm{mg} / \mathrm{mL})$ was statistically significant $(\mathrm{P}<0.01)$. The difference at $5 \mathrm{hrs}$ between $100 \mu \mathrm{g} / \mathrm{mL}$ and $1 \mathrm{mg} / \mathrm{mL}$ groups was also statistically significant $(\mathrm{P}<0.01)$, indicating that dose-response exists in the suppression of bacterial growth. In contrast, little difference was observed in the group treated with $\mathrm{ZnS}: \mathrm{Mn}$-Cys. This is interesting as the nature of the amino acid used for capping can lead to a significant difference in cytotoxicity. To confirm that the bacterial cells used in this experiment are also inhibited by antibiotics, different concentrations of ampicillin was evaluated for growth inhibition. The results indicate that $12.5 \mu \mathrm{g} / \mathrm{mL}$ can be considered as minimum inhibitory concentration (Figure 4C) and $\mathrm{IC}_{50}$ of ampicillin in the same bacterial culture was determined to be $5 \mu \mathrm{g} / \mathrm{mL}$ (Figure 4D). Taken together, it can be suggested that cysteine, a thiol residue-containing amino acid, may be safer than histidine in encapsulating the toxic components of nanocrystal.

Next, to see if similar findings can be replicated in human cells, a colorimetric assay for the quantification of cell proliferation and viability based on the cleavage of the tetrazolium salt (WST-1) by mitochondrial dehydrogenase in viable cells was carried out in human lung (IMR90) and kidney (HEK293) cells. As shown in Figure 5, similar patterns of suppression were observed in both cell lines. At $1 \mathrm{mg} / \mathrm{mL}$ concentration of either ZnS:Mn-Cys or ZnS:Mn-His nanocrystal, statistically significant inhibition of cell proliferation and viability $(\mathrm{P}<0.001)$ was observed, which was less than the etoposide group (apoptosisinducing agent). However, at $100 \mu \mathrm{g} / \mathrm{mL}$ concentrations, statistically significant suppression $(\mathrm{P}<0.05)$ could be found only in ZnS:Mn-His nanocrystal, again implying that $\mathrm{ZnS}: \mathrm{Mn}-\mathrm{His}$ may be more cytotoxic than ZnS:Mn-Cys nanocrystal. Also, dose-response in the range of 10 to 100 to $1000 \mu \mathrm{g} / \mathrm{mL}$ was observed for ZnS:Mn-His nanocrystal in both cell lines $(\mathrm{P}<$ 0.01). In another aspect, HEK293 cells, which were derived from human embryonic kidney, appeared to be more sensitive to cytotoxic effects than IMR90 cells (fetal lung fibroblasts). In addition, inhibition of IMR 90 and HEK293 cells at $1 \mathrm{mg} / \mathrm{mL}$ concentration of $\mathrm{ZnS}: \mathrm{Mn}-\mathrm{Cys}$ nanocrystal, which was not seen with $E$. coli, suggests that human cells may be affected by the dose of the nanocrystal that could not suppress bacterial growth.

Taken together, $\mathrm{ZnS}: \mathrm{Mn}$-His showed cytotoxicity both in bacterial and human cells at relatively high doses, but ZnS:MnCys did not affect bacterial growth and human cells at doses less than $100 \mu \mathrm{g} / \mathrm{mL}$. These results again argue for the importance of using appropriate amino acid for the capping of hydrophobic surfaces of $\mathrm{ZnS}: \mathrm{Mn}$ nanocrystals.

Cysteine is regarded as an important source of sulfide in human metabolism, and the thiol group of the cysteine is nucleophilic and easily oxidized under basic conditions. ${ }^{22}$ The thiol group is also known to have a high affinity for heavy metals, so that proteins containing cysteine residue, such as metallothionein, will bind metals such as mercury, lead, and cadmium quite strongly. ${ }^{23}$ Histidine, one of the essential amino acids in human infants, contains a unique imidazole side chain. The imidazole side chain of histidine is a coordinating ligand in metalloproteins and is a part of catalytic sites in certain enzymes. In addition, the imidazole side chain of histidine has a $\mathrm{p} K_{\mathrm{a}}$ value of app- 

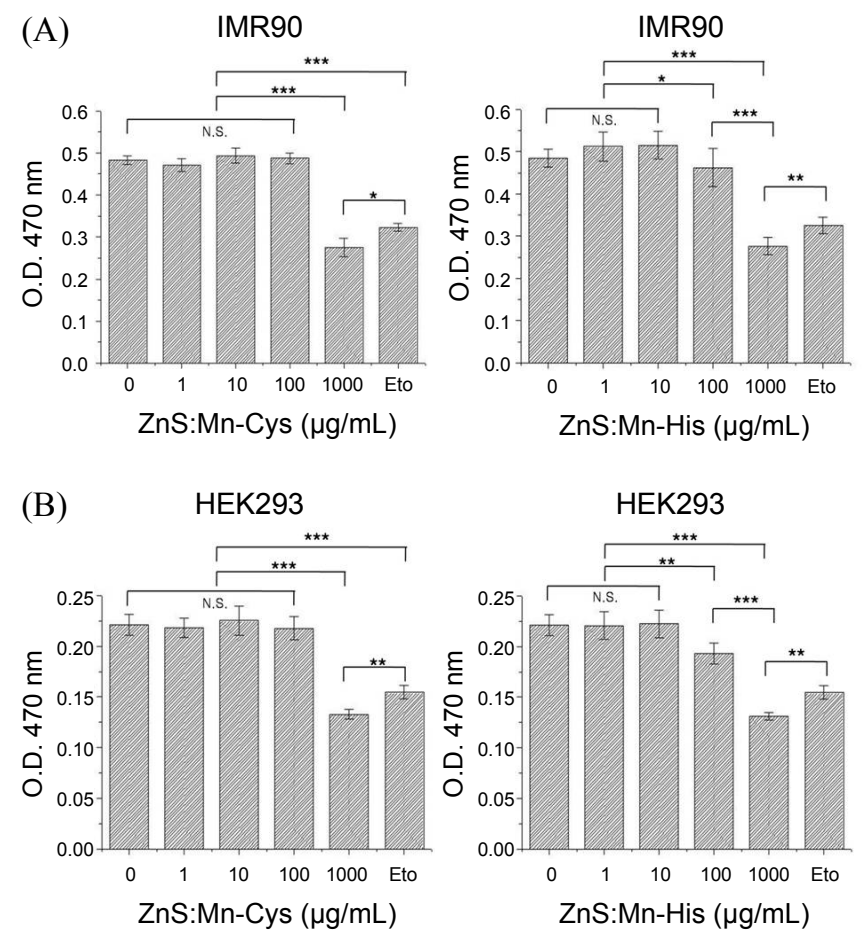

Figure 5. Effect of amino acid-capped ZnS:Mn nanocrystals on proliferation and viability of human cells, IMR 90 (A) and HEK293 (B).

roximately 6 , and, overall, the amino acid has a $\mathrm{p} K_{\mathrm{a}}$ of 6.5 ; therefore, relatively small shifts in $\mathrm{pH}$ will affect its average charge in a solution. The imidazole ring of histidine is aromatic at all $\mathrm{pH}$ values, and the six pi electrons can form a $\pi$ stacking interaction. $^{24}$

In our case, the cysteine surface capped $\mathrm{ZnS}: \mathrm{Mn}$ nanocrystal showed less toxicity than histidine capped one. It can be speculated that cysteine, containing a thiol residue, may be better in encapsulating the toxic components. It is obvious that sulfur atom in the cysteine molecule, which contains empty $d$ orbitals, has stronger binding affinity against transition metal ions than pi-donating aromatic rings such as imidazole molecule in the histidine. It can be also referred to soft and hard interaction differences of $\mathrm{Zn}$ to $\mathrm{S}$ atom versus $\mathrm{Zn}$ to pi-ring in the corresponding nanocrystals. ${ }^{25}$ It is hard to speculate how many cysteine or histidine molecules are actually coordinated on the surface of the nanocrystal; however, the strongly coordinated cysteine molecules are probably more efficiently preventing dissolution of $\mathrm{Zn}$ ions from the nanocrystal lattices, which causes toxic effect on the growth of E. coli and other human cells.

Recently, semiconductor quantum dots (QDs) have received much attention as a novel type of fluorophore for biomedical imaging. Since amino acid capping of water-soluble $\mathrm{ZnS}: \mathrm{Mn}$ semiconductor nanocrystals can provide a novel platform on which to attach many biomolecules, such as DNA, RNA, and proteins, they can be used for a variety of applications, including biosensors. In an earlier study, the synthesis and optical characterization of water dispersible L-valine capped $\mathrm{ZnS}$ :Mn nanocrystals and the crystal structure of the precursor $\left[\mathrm{Zn}(\mathrm{Val})_{2}\right.$ $\left(\mathrm{H}_{2} \mathrm{O}\right)$ ] complex have been reported, showing that an amino acid ligand can be a promising biocompatible capping agent for semiconductor nanocrystals. ${ }^{26}$ In this study, water soluble amino acid-capped ZnS:Mn nanocrystals indeed showed sufficient physical and chemical properties suitable for biological applications. However, as demonstrated here, the nature of the amino acid ligands used for capping $\mathrm{ZnS}: \mathrm{Mn}$ nanocrystals may be important in terms of reducing cytotoxicity. Further optimization of nanocrystals is warranted.

\section{Conclusion}

Cysteine and histidine-capped water-dispersible $\mathrm{ZnS}: \mathrm{Mn}$ nanocrystals ( $\mathrm{ZnS}: \mathrm{Mn}-\mathrm{Cys}$ and $\mathrm{ZnS}: \mathrm{Mn}$-His) were synthesized and their effects on $E$. coli and human cells were investigated. Their physical and optical properties were measured thoroughly by spectroscopic methods. In biological tests, the $\mathrm{ZnS}: \mathrm{Mn}-\mathrm{His}$ nanocrystals significantly suppressed the growth of $E$. coli at $100 \mu \mathrm{g} / \mathrm{mL}$ and $1 \mathrm{mg} / \mathrm{mL}$ concentrations, something not observed with ZnS:Mn-Cys. Consistent with this, greater inhibition of cell proliferation and viability was observed in HEK293 and IMR90 cells in ZnS:Mn-His at $100 \mu \mathrm{g} / \mathrm{mL}$ and $1 \mathrm{mg} / \mathrm{mL}$ concentrations. This implies that water-dispersible nanocrystals can have their cytotoxic effects adapted by the choice of amino acids used for surface modification. An effective means of blocking inner zinc ions would provide safer nanocrystals that could be used in biomedical applications.

Acknowledgments. This work was supported by the Korea Research Foundation Grant funded by the Korean Government (MOEHRD, Basic Research Promotion Fund) (KRF-2008331-E00108), and this present research was also supported by the GRRC program, Gyeonggi Province; [GRRC-Dankook2010-B02] grant awarded for C.-S. Hwang.

\section{References}

1. Alivisatos, A. P. J. Phys. Chem. 1996, 100, 13226.

2. Weller, H. Angew. Chem. Int. Ed. Engl. 1993, 35, 1079

3. Milliron, D. J.; Alivisatos, A. P.; Pitois, C.; Edder, C.; Fréchet, J. M. J. Adv. Mater. 2003, 15, 58.

4. Brus, L. E. Appl. Phys. A 1991, 53, 465.

5. Hwang, J. M.; Oh, M. O.; Kim, I.; Lee, J. K.; Ha, C. S. Curr. Appl. Phys. 2005, 5, 31 .

6. Yu, S. H.; Wu, Y. S.; Yang, J.; Han, Z.; Xie, Y.; Qian, Y.; Liu, X. Chem. Mater. 1998, 10, 2309.

7. Gerion, D.; Pinaud, F.; Williams, S. C.; Parak, W. J.; Zanchet, D.; Weiss, S.; Alivisatos, A. P. Phys. Chem. B 2001, 105, 8861.

8. Jun, Y. W.; Jang, J. T.; Cheon, J. Bull. Korean Chem. Soc. 2006, 27, 961 .

9. (a) Park, C.; Kim, D. H.; Kim, M. J.; Yoon, T. H. Bull. Korean Chem. Soc. 2008, 29, 303. (b) Dua, P.; Jeong, S.; Lee, S. E.; Hong, S. W.; Kim, S.; Lee, D. K. Bull. Korean Chem. Soc. 2010, 31, 1555.

10. Kho, R.; Nguyen, L.; Torres-Martínez, C. L.; Mehra, R. K. Biochem. Biophys. Res. Commun. 2000, 272, 29.

11. Mitchell, G. P.; Mirkin, C. A.; Letsinger, R. L. J. Am. Chem. Soc. 1999, 121,8122

12. Chen, C. C.; Yet, C. P.; Wang, H. N.; Chao, C. Y. Langmuir 1999, 15,6845

13. Bae, W.; Mehra, R. K. J. Inorg. Biochem. 1998, 70, 125.

14. Bhargava, R. N.; Gallagher, D. Phys. Rev. Lett. 1994, 72, 416.

15. Lee, J. H.; Kim, Y. A.; Kim, K.; Huh, Y. D.; Hyun, J. W.; Kim, H. S.; Noh, S. J.; Hwang, C. S. Bull. Korean Chem. Soc. 2007, 28, 
1091

16. Lee, J. H.; Kim, Y. A.; Kim, K.; Huh, Y. D.; Hyun, J. W.; Kim, H. S.; Noh, S. J.; Hwang, C. S. Bull. Korean Chem. Soc. 2007, 28, 1091 .

17. Yi, G.; Sun, B.; Yang, F.; Chen, D. J. Mater. Chem. 2001, 11, 2928.

18. Bhargava, R. N.; Gallagher, D.; Hong, X.; Nurmikko, A. Phys. Rev. Lett. 1994, 72, 416.

19. Williams, A. T. R.; Winfield, S. A.; Miller, J. N. Analyst 1983, 108, 1067.

20. Zhuang, J.; Zhang, X.; Wang, G.; Li, D.; Yang, W.; Li, T. J. Mater.
Chem. 2003, 13, 1853.

21. Moszczenski, C. W.; Hooper, R. J. Inorg. Chim. Acta 1983, 70, 71.

22. Bulaz, G.; Kortemme, T.; Goldenberg, D. P. Biochem. 1998, 37 , 8965.

23. Baker, D. H.; Czarnecki-Maulden, G. L. J. Nutr. 1987, 117, 1003.

24. Wang, L.; Sun, N.; Terzyan, S.; Zhang, X.; Benson, D. R. Biochem. 2006, $45,13750$.

25. Jorgensen, K. C. Inorg. Chem. 1964, 3, 1201.

26. Hwang, C. S.; Lee, N.; Kim, Y. A.; Park, Y. B. Bull. Korean Chem. Soc. 2006, 27, 1809. 